\title{
Investigating the Engagement of Mature Students with Mathematics Learning Support
}

\author{
Cormac Breen \\ Technological University Dublin, cormac.breen@tudublin.ie \\ Michael Carr \\ Dublin Institute of Technology, michael.carr@tudublin.ie \\ Mark Prendergast \\ University of Dublin, Trinity College
}

Follow this and additional works at: https://arrow.tudublin.ie/scschmatart

Part of the Mathematics Commons, and the Science and Mathematics Education Commons

\section{Recommended Citation}

Breen, C., Carr, M., Prendergast, M., (2015) Investigating the Engagement of Mature Students with Mathematics Learning Support, Teaching Mathematics and its Applications, 34 (1): 16-25 (2015) doi:

10.1093/teamat/hru027

This Article is brought to you for free and open access by the School of Mathematics at ARROW@TU Dublin. It has been accepted for inclusion in Articles by an authorized administrator of ARROW@TU Dublin. For more information, please contact arrow.admin@tudublin.ie, aisling.coyne@tudublin.ie,gerard.connolly@tudublin.ie.

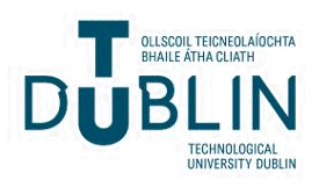




\title{
Investigating the Engagement of Mature Students with Mathematics Learning Support
}

\author{
Cormac Breen*, Mark Prendergast ${ }^{\mathbb{I I}}$ and Michael Carr* \\ *Dublin Institute of Technology, Dublin, Ireland and IT Trinity College Dublin, Dublin, Ireland
}

\begin{abstract}
The Maths Learning Support Centre (MLSC) in the Dublin Institute of Technology (DIT) provides free mathematical support to all DIT students. This support is primarily delivered through a drop-in service, where students can receive one-to-one tuition, without an appointment, in any area of mathematics. In the first semester of the 2013/14 academic year a significant proportion of students that availed of this drop-in service were mature students enrolled in Engineering programmes. This is of particular interest as mature students constitute a relatively small proportion of the total student body, motivating a deeper study of the reasons for the high levels of engagement in this cohort. To this end two focus groups were conducted, consisting of those who do and do not attend the MLSC. Particular interest was paid to the motivations of student who attend and the reasons given by those who do not. The motivations of mature students were found to be multifaceted while the reasons for non-engagement were mostly in line with the literature. In addition some quantitative analysis was carried to determine what effect the MLSC had on student's academic performance.
\end{abstract}

\section{Introduction}

In recent years an increasing number of students in Irish Higher Educational Institutions (HEIs) are taking courses with mathematical and statistical elements. This is in part due to the widespread recognition that mathematics underpins many other disciplines (such as Science, Technology and Engineering) and the emphasis placed by the Higher Educational Authority on producing graduates who are highly literate in mathematics (EGFSN 2008, HEA 2011).

Hand in hand with this increase however has come the so called 'Maths Problem'- that is a decline in the mathematical proficiency of incoming first year students across HEIs in Ireland and elsewhere (Gill 2010, Almeida et al. 2012, Carr et al. $2013 \&$ 2013). This in turn is having a detrimental effect on enrolment and retention levels in science and technology courses in HEIs (OECD 1999). In fact, it is widely acknowledged that the absence of a solid foundation in mathematics can be one of the key inhibitors for student progression in higher education (HEA 2010).

As part of the response to this problem, Maths Learning Support Centres (MLSCs), defined by Lawson et al (2003) as 'a facility offered to students (not necessarily of mathematics) which is in addition to their regular programme of teaching through lectures, tutorials, seminars, problems classes, personal tutorials, etc.' have been set up in the majority of HEIs in Ireland (Gill et al. 2008). In the UK over $85 \%$ of HEIS surveyed offer some form of Maths Learning Support (MLS) (Perkin et al. 2012), up from $62.3 \%$ in 2004 and 48\% in 2001 (Perkin et al. 2004, Lawson et al. 2001). It is therefore clear that MLS has now become an integral part of the higher educational framework, both in Ireland and the UK.

However despite this, MLSCs in several HEIs exist precariously, often lack permanent funding and are regularly in the 'front line' for spending cut backs 
(MacGillivray \& Croft 2011, Mac an Bhaird et al. 2013). To ensure that the limited funding available for MLS is put to the best possible use and to establish 'Best Practice', much time and resources have been put into researching methods of evaluating MLSCs' activities. This evaluation can be undertaken using quantitative (usage figures, diagnostic testing, exam results etc.) and qualitative methods (focus groups, surveys, student feedback etc.) (Macgillivray \& Croft 2011). In a study on evaluation of the MLSC in Dublin City University, Ní Fhloinn found that a combination of both types of methods gave a more complete picture (Ní Fhloinn 2009). An extensive review of the literature on the evaluation of MLSCs can be found in (Matthews et al. 2012).

One important issue that arises from these evaluations is the non-engagement with MLS of so called 'at risk' students - those who are most in need of extra support. In a recent paper by Mac an Bhaird et al. (2013), details of a large scale study on student non-engagement with MLS across several Irish HEIs are given. The study found that the main reason students gave for non-engagement was that they did not need help. However this was more likely to have come from a student with a strong mathematical background. For the weaker 'at risk' students, issues with the structures of the MLS such as unsuitable opening hours or a lack of information were more likely to be cited as a reason for non-attendance. Symonds (2008) questions whether these reasons are valid and wonders if implementing the requested changes in structures would actually serve to increase the engagement levels of these students. This suggests that a deeper study into the reasons of student non-engagement with MLS, in particular for those 'at risk' students, is required to get to the root of the non-engagement problem.

In this paper, the authors seek to further this investigation by looking at the engagement levels of mature students with the MLSC in the Dublin Institute of Technology (DIT). In the DIT a mature student is defined as being 'any Irish or EU citizen who will be 23 years of age on the 1st of January of the proposed year of entry' (DIT Website). The authors examine qualitatively the reasons behind both the engagement and non-engagement of this cohort of students with the MLSC, as well as performing a quantitative study on the effect of the MLSC on these students' academic performance.

\section{Methods}

This study seeks to examine the reasons behind both the engagement and nonengagement of students with the MLSC in the DIT, as well as investigating how the MLSC has influenced the academic performance of mature students who have regularly availed of its services. The authors decided to use a mixed method approach by combining both quantitative and qualitative methods of research. Qualitative researchers are interested in understanding the meaning people have constructed from their lived experiences (Merriam, 2009). Hence, qualitative methods of enquiry and analysis are more suitable when humans are the instruments of enquiry. This is why the authors decided on a study of this nature. However, in order to evaluate the academic progress of mature students who have been attending the MLSC a quantitative measure is needed. Much research supports this integration of quantitative and qualitative research. 
The use of multiple methods reflects an attempt to secure an in-depth understanding of the research and allows for broader and better results (Denzin and Lincoln, 2005).

\subsection{Participants}

The participants for this study comprised of mature students in their first year of an Engineering undergraduate programme in the DIT. As mentioned previously, in the DIT a mature student is defined as being 'any Irish or EU citizen who will be 23 years of age on the 1st of January of the proposed year of entry'.

\subsection{Qualitative Data}

In order to get feedback regarding why students attend/do not attend the MLSC, two focus groups were conducted. The first group (Focus Group 1) was made up of mature students whose attendance in the MLSC was constant throughout the year. The second group (Focus Group 2) was made up of mature students who had never attended the MLSC. Each student was coded to ensure confidentially. There were ten students in Focus Group 1 (A1 - A10) and four students in Focus Group 2 (N1 - N4). Their responses were transcribed and arranged into themes by the authors.

\subsection{Quantitative Data}

In order to get a quantitative measure of how the MLSC influenced the academic performance of mature students who regularly availed of its services, the authors decided to compare the grades of mature students who attended the MLSC with those who did not. The objective was to investigate if the MLSC had any effect on their grades. The authors understand that there may have been other variables which may have affected the students' grades throughout the year. The study focused on one particular group of students, who were undertaking their first year of an ordinary degree in mechanical engineering and compared the end of semester exam results of those in this group who did and did not attend the MLSC in that semester. There were 20 mature students in this cohort. Of these students 8 had attended the MLSC and 12 had never attended. The 8 students who attended the MLSC were regular attenders; the average number of visits among this group over the course of the 2013/2014 academic year was 13.

\section{Results and Findings}

\subsection{Focus Group Findings}

In this section the main themes that arose during the focus groups are outlined. There will be particular focus on the three topics most relevant to this paper namely what motivates mature students to attend the MLS, the reasons given by these students for non-attendance and their attitudes towards traditional students.

\subsubsection{Motivation}

During the course of the focus group, it became clear that the motivations of mature students who attend the MLSC were multi-faceted. 
The initial motivations that were raised were of a practical nature, such as financial motivation (not being able to afford private tuition) or simply a lack of availability of any other form of support

A1: I didn't even do a Junior Cert and I'm doing mechanical engineering maths and I've had straight A's through and that's through the Learning Centre you know. I can't afford grinds you know.

A2: There's no other, no other help available. That's what I found. If you're looking for extra help as well, every door would be closed.

An interesting theme that arose was the concept that it was the nature of mathematics itself, and its difference from other subjects, which motivated students to seek extra help. They experienced difficulties with self-study and keeping up with the pace of lectures.

A1: Whereas maths, you have something at the start of a page and something at the end and if you don't understand the bit in the middle, unless somebody points their finger at it and says to you "this is what's happening". If you don't get it you don't get it.

A1: I find with maths in particular of all the subjects..... Unless you get a hold of the stuff in September and you're doing October's work you haven't a hope, if you don't understand the basics of stuff you haven't a hope. So I found going to the learning centre each week, staying on top, learning whatever was current, you'd go in and you'd actually learn from the lecture as well.

Related to this theme, some students stated that while they found self-study aids (such as textbooks or online mathematical resources) useful, it was their belief that these aids are not a replacement for one-to-one support, such as that offered in the MLSC.

A2: They're all fairly good but you still need the one-on-one. Because you can keep pausing and rewinding and going backwards and forwards but you need the one-onone.... When you've got no basic level there's only so much a video or a book can teach you

A widely held view among the participants was that the mature students' life experiences serve to motivate them to seek out the extra support offered by the MLSC.

A9: the clock is ticking and most of us have been out in the real world and most of us want to achieve something....if I need that extra bit of support, which you do get in the Maths Support Centre then I'll take advantage of it.

A7: it's that experience of having been at the bottom, you know and having to try and survive at the bottom, that you realise that when you get an opportunity like this, just how important it is to really avail of all the services, in my opinion the Maths Learning Centre being the most important that I've come across so far as an extra aid on top of your coursework and stuff like that.

It is a stated aim of the MLSC (MLSC website) to provide MLS to students in an informal, relaxed and non-judgemental manner. Such an environment enables the students to raise their confidence in mathematics and hence develop as independent learners. The responses of the focus groups show that this goal is being achieved. 
A10: You can ask the question three or four times say if you still don't get it, there's no kind of feeling embarrassed to keep on asking, they'll keep on explaining it to you until you actually understand what you're actually doing so it is, it's a very relaxed environment so I find it very good that way.

Finally, the participants noted that they are not just interested in passing the exams, but that they wish to gain a deeper understanding of the subject. They recognise, again possibly based upon their life experiences, the importance of possessing more than just a surface level knowledge of their chosen subject area.

A9: but I want to be able to understand it you know, I want to be able to like if I go to a job interview and somebody puts a problem in front of me I want to be able to know what it's about....... I want to comprehend it basically and if I need that extra bit of support, which you do get in the Maths Support Centre then I'll take advantage of it.

\subsubsection{Reasons for Non-Engagement}

This section outlines the main reasons given for the non-engagement of mature students with the MLSC. In a recent large scale survey on the issue of student non-engagement with MLS in Irish HEIs, it was found the main reason given by students who did not avail of service was that they did not believe they needed it (Mac an Bhaird et al. 2013). This finding was supported in our study.

N3: I haven't really had a problem that I couldn't track down an answer to myself with google, youtube or any of that.

Mac an Bhaird et al (2013) found that the second most common reason given for nonattendance were issues with the structural organisation of MLS in their HEI e.g. opening hours, room size etc. This theme also arose during our study.

N3: if it was at a different time during the day that would suit me.

A7: I found that the only thing that kind of stopped me from going was the size of the room and at certain times because of how packed it is

It should be noted that participant A7 had attended the MLSC at other times.

During the focus groups, it was noted that mature students who have attended a course prior to undertaking their undergraduate degree (such as a Further Education and Training Awards Council (FETAC) Level 5 course as mentioned by participant N1 below) appear to have less of a need for the services of the MLSC then those who have entered directly into their undergraduate programme.

N3: Some mature students have a problem I think. Since they finished the LC and come back into college it has been 5-10 years. Not studied anything... I did last year mechanical engineering, this year I am ok.

N1: I wasn't too bad because I did FETAC 5 last year and it had engineering maths in it as well. 


\subsubsection{Perception of Traditional Students}

As stated in the abstract, the engagement levels of the mature student are much greater than that of the traditional student. In this final section we will outline the views of our participants on both this discrepancy and traditional students in general.

There appears to be a perception among mature students that traditional students, having come straight from second level, are better prepared for the material in the programmes, in particular the mathematical aspects. Hence, they may not need the services of the MLSC as much as the mature student.

A6: all the students that came straight from the leaving cert they'll just all get it, they'll understand it all in those two hours where I'll just sorta pick it up at the end cause I haven't done it in years

A7: and we're starting right from the bottom and we have not done it in years

The participants also raised the point that the non-compulsory nature of MLS may have a negative effect on engagement with the traditional student

A1: I think an awful lot of them as well maybe would have intentions of going to the learning centre but it would eat into their social time. I mean an awful lot of them don't go to lectures

A5: they don't have to go so they don't bother.

They noted that perhaps the inexperience and lack of confidence of youth could have a negative effect on engagement. The traditional student may tend to be more reticent about asking for help than the mature student would be.

A9: I know for a fact that a lot of them are struggling but they just don't realise the opportunity that is there you know and they are too young to take advantage of it.

A10: I just think they are intimidated to ask for help whereas mature people like ourselves we want to pass so we know we have to do it... We're not afraid to go here look I need help and ask for it and stuff

It is perhaps worth noting here the different impressions of participants A6 and A9 towards the mathematical ability of tradational students.

The final viewpoint that was raised was on peer support. The participants noted that, in their experience, the traditional student would rely more on peer support than the mature student. They are more likely to work together in large groups and hence are less in need of MLS than a mature student may be.

A1: but they pick an awful lot of stuff up off each other as well whereas if they're struggling with something if you are sitting around with ten or fifteen of the lads you know what I mean, they would talk about things a bit more they would but mature students would tend to stay in smaller groups you know what I mean and you would share stuff, you would learn stuff off each other but not as quick as the younger lads.

\subsubsection{Suggestions}

The participants were also asked to give suggestions on how to improve both the services offered by the MLSC and student engagement levels with the Centre. 
It was suggested that it might be a more efficient use of resources if the MLSC were to offer extra tutorials on areas of common weakness.

A4. Yeah. Maybe a topic tutorial might be helpful considering the last day we were up there like eight or nine of us were studying integration. So something to that effect.

On the issue of raising engagement levels among students, the participants noted that once students attend the Centre initially and see the services offered there, then they are more than likely to attend again.

A7. The difficult part seems to be in getting people to go for the first time, getting the over that initial hump like, just to go up once even and see what it's like... There doesn't seem to be anybody who has gone once or twice and then realised that they're not interested. If they go, they stay going

\subsection{Quantitative Findings}

The study focused on one particular group of students, who were undertaking their first year of an ordinary degree in mechanical engineering and compared the end of semester exam results of those in this group who did and did not attend the MLSC in that semester. There were 20 mature students in this cohort. Of these students 8 had attended the MLSC and 12 had never attended. Of the 8 students who attended, 2 dropped out of the course after the first few weeks so there was no data on their performance. For the 18 students who remained, their performance in the semester 1 mathematics module was compared (See Table 1).

The average mark of those who attended the MLSC was higher but not significantly so ( $\mathrm{t}$ test, $\mathrm{p}=0.25$ ). It is not possible to determine if the two groups were the same or different to begin with as many of these students are international students, and many of the Irish students had not finished secondary school. Hence there is no single metric to compare their mathematical ability on entry. There is a DIT mathematics diagnostic test given to many students on entry but it was not given to this cohort.

\begin{tabular}{|l|l|l|l|}
\hline Attended MLSC & N & Mean & Standard deviation \\
\hline Yes & 6 & 80.6 & 18.9 \\
\hline No & 12 & 68.4 & 23 \\
\hline
\end{tabular}

Table 1: A comparison of end of semester exam results of those who did/did not attend the MLSC.

In addition, the proportion of both groups of students that achieved a grade of more than $60 \%$ was examined (See Table 2). All the students who attended the MLSC achieved a mark of greater than $60 \%$. However, using Fishers exact test, it was found that the difference in these proportions was again not statistically significant $(\mathrm{p}=0.52)$. 


\begin{tabular}{|l|l|l|l|}
\hline Attended Centre & N & $>60$ & $<60$ \\
\hline Yes & 6 & 6 & 0 \\
\hline No & 12 & 9 & 3 \\
\hline
\end{tabular}

Table 2: A comparison of the proportion of students who did/did not attend the MLSC who achieved a mark higher/lower than $60 \%$.

It is a limitation of this study that this analysis was only for a small number of students in one course. The two students who attended but dropped out early are excluded and there is no metric for ranking the students on entry.

Of course, one must be cautious when attempting to determine the effect that attending the MLSC has on students' grades. It is possible that those who attend the MLSC, because of their work ethic, engagement, motivation etc., would perform well in exams anyway, even in the absence of the MLSC.

\section{Conclusions}

In this paper the authors investigated the reasons behind both the attendance and nonengagement of mature students with the MLSC in the DIT. Two focus groups were conducted with some interesting qualitative findings. The motivations of mature students were found to be multi-faceted, ranging from practical reasons, such as financial motivation, to more complex reasons such as their life experiences as adults motivating them to seek out extra help. The notion that mature students are interested not just in passing their exams, but also in gaining a deeper understanding of their chosen subjects was raised. The importance of one-to-one support in a student's development as an independent learner, even with the widespread availability of online resources, was also stressed.

For those students who did not avail of the services offered by the MLSC, the reasons given were mostly in line with the literature (Mac an Bhaird et al 2013), for example a lack of need for the service or issues with the structures of the MLSC. An interesting point raised was that mature students who have had a transition year prior to beginning their programme may have less need for extra support than those who have not attended such a course.

The participants were also asked to give their thoughts on the low engagement levels of traditional students. They noted that traditional students, having come straight from second level, are generally better prepared for third level mathematics. The noncompulsory nature of MLS as well as the reticence of younger students to seek extra support, were also cited as possible reasons for non-engagement. The final issue raised was the notion that traditional students tend to rely more on peer support, e.g. studying in groups, than the mature student would and hence would have less need for the extra support offered by the MLSC. 
Finally the participants were asked for any suggestions they may have on improving both the services offered by the MLSC and the engagement levels with the MLSC. It was suggested that group tutorials on areas of common weakness should be run, this service is available in several other HEIs and the MLSC intends to offer such tutorials in the coming academic year. It was also noted that once a student has attended the MLSC once and seen the services on offer, then they are very likely to attend again. As a result of this, the MLSC is now included in the 'tour of facilities' that is conducted during Student Induction Week.

On the quantitative side, the authors examined the end of semester exam results of one group of students. They found that while the mean grade of those who attended the MLSC was higher than those who did not, the difference was not statistically significant $(p=0.25)$. In addition the difference between the proportion of both groups that achieved over $60 \%$ in the end of semester exam was not statistically significant $(\mathrm{p}=0.52)$. These results must be viewed with a certain amount of caution however, as there was no common baseline for comparison of students' exams scores (e.g. diagnostic test results) and the sample size was small and is not random.

\subsection{Future Work}

The authors intend to conduct focus groups involving traditional students to investigate the non-engagement further. The authors also wish to extend the quantitative analysis of this study to a much larger group of students, including tradational students, and to benchmark students on entry using the DIT mathematics diagnostics test, in line with Carr et al. (2013).

\section{Acknowledgements}

The authors wish to acknowledge the students who participated in this study. The authors would also like to thank the reviewers for their helpful comments.

\section{References}

Almeida, B .D, Fidalgo, E., Rasteiro C., D.M.L.D. (2012) Projeto “ACAM - Avaliação de Competências / Ações de Melhoria”,XIX Colóquio AFIRSE: Revisitar os es tudos Curriculares : onde estamos e para onde vamos?,

Carr, M., Bowe, B., \& Ní Fhloinn, E. (2013) “Core Skills Assessment to improve mathematical competency", European Journal of Engineering Education, pp.1-12.

Carr, M., Ni Fhloinn, E., Murphy, E. \& Bowe, B. (2013) Addressing continuing mathematical deficiencies with advanced mathematical diagnostic testing.Teaching Mathematics Applications 32 (2): 66-75.

Denzin, N.K. and Lincoln, Y.S. (2005) The SAGE Handbook of Qualitative Research, USA: Sage Publications

Dublin Institute of Technology (DIT) [online], (Retrived April 2014 from http://www.dit.ie/study/mature/prospective/)

Expert Group on Future Skills Needs. (2008) Statement on Raising National Mathematical Achievement. Retrived April 2014 from http://www.skillsireland.ie/media/egfsn090616_statement_on_activity.pdf)

Gill, O., Johnson, P. \& O’Donoghue, J. (2008) An Audit of Mathematics Support Provision in Irish Third Level Institutions. CEMTL (Regional Centre For Excellence in Mathematics Teaching and Learning), University of Limerick. 
Gill, O., O’Donoghue J., Faulkner, F. \& Hannigan A. (2010) Trends in performance of science and technology students. International Journal of Maths Education, Science and Technology, 41, 323-339.

A Study in Progression in Irish Higher Education, HEA (2010). Retrived April 2014 from http://www.hea.ie/sites/default/files/study_of_progression_in_irish_higher_education_2010.pdf

National Strategy for Higher Education to 2030, (2011) Retrived April 2014 from http://www.hea.ie/sites/default/files/national_strategy_for_higher_education_2030.pdf

Lawson, D., Croft, T. \& Halpın, M. (2001) Evaluating and Enhancing the Effectiveness of Mathematics Support Centres. Final report of a project funded by the LTSN Maths, Stats and OR Network. Retrived April 2014 from http://www.academia.edu/2715644/Evaluating_and_Enhancing_the_Effectiveness_of_Mathemat ics_Support_Centres

Lawson, D., Croft, A.C. \& Halpın, M. (2003) Good practice in the provision of mathematics support centres, learning and teaching in mathematics, statistics and operational research. LTSN Maths, Stats \& OR Network, (Retrived April 2014 from http://www.mathcentre.ac.uk/resources/Good\%20Practice\%20Guide/goodpractice2E.pdf).

Mac An Bhaird, C., Fitzmaurıce, O., Ní Fhloınn, E. \& O’Sullıvan, C. (2013) Student non-engagement with mathematics learning supports Teaching Mathematics and Its Applications (2013) 32, 191 205

Macgillıvray, H. \& Croft, A. C. (2011) Understanding evaluation of learning support in mathematics and statistics. Int. J. Math. Educ. Sci. \& Tech., 42, 189-212.

Matthews, J., Croft, T., Lawson, D. \& Waller, D. (2013) Evaluation of mathematics support centres: a literature review. Teaching Mathematics and Its Applications (2013) 32, 173-190

Merriam, S.B. (2009). Qualitative Research: A Guide to Design and Implementation, San Francisco: Jossey - Bass Publishers.

Mathematics Learning Support Centre- Aims [online] Retrieved April 2014 from http://www.maths.dit.ie/mlsc/aims.html

Ní Fhloinn, E. (2009) The role of student feedback in evaluating mathematics support centres. CETLMSOR Conference 2009 Proceedings, 94-98, Retrived April 2014 from http://www.mathstore.ac.uk/headocs/Proceedings_2009_Upload_0.pdf

Organısation For Economic Co-Operation And Development (OECD). (1999) Measuring Student Knowledge and Skills: A New Framework for Assessment. Paris: OECD.

Perkın, G. \& Croft, T. (2004) Mathematics Support Centres - the extent of current provision. MSOR Connections, 4 (2) 14-18.

Perkin, G., Lawson, D. \& Croft, T. (2013) The extent of mathematics learning support in UK higher education - the 2012 survey. Teaching Mathematics Applications (2013) 32 (4): 165-172

Symonds, R. (2008) Evaluating Students' Engagement with Mathematics Support. PhD Thesis. Loughborough University.

Cormac Breen is the coordinator of the Mathematicss Learning Support Centre (MLSC) in the Dublin Institute of Technology (DIT). He holds a degree and a masters in Theoretical Physics from University College Dublin (UCD) and completed his PhD in Theoretical Physics, also in UCD, in 2011. He has lectured and tutored in mathematics in both UCD and DIT, and has been the coordinator of the MLSC since May 2013. He conducts research in the areas of Mathematics Education and Theoretical Physics.

email:cormac.breen@dit.ie

Mark Prendergast Mark Prendergast is an Assistant Professor in mathematics education in Trinity College Dublin. He is qualified as a second level mathematics teacher from the University of Limerick in 2003 and completed his PhD in Mathematics Education, also in the University of Limerick, in 2011. He has worked in the National 
Centre for Excellence in Mathematics and Science Teaching and Learning (NCEMSTL) for two years and has also coordinated the Mathematics Leaning Centre in the University of Limerick. His current research interests lie in promoting student interest and achievement in mathematics through effective teaching of the subject.

email: mark.prendergast@tcd.ie

Michael Carr is a lecturer in Mathematics and Statistics in the College of Engineering and Built Environment in the Dublin Institute of Technology. His research interests include the first year experience of students, development of core mathematical skills in university students, and mathematics education for engineers

email:michael.carr@dit.ie 